\title{
Mothering A Child with Mental Disability in Egyptian Culture: Perceptions of Stigma
}

\author{
Maha Elsinbawi, MPA $^{1^{*}}$, Nagwa A. Meguid, $\mathrm{PhD}^{2}$ \\ ${ }^{1}$ M.A. in Human Behavior, National University in San Diego, USA, and M.Sc. of Public Administration, Cairo University, Egypt \\ ${ }^{2}$ Professor of Human Genetics and special Needs, NRC, Egypt
}

DOI: $10.36348 /$ sjhss.2020.v05i09.006 $\quad$ | Received: 13.09.2020 | Accepted: 21.09.2020 | Published: 25.09 .2020

*Corresponding author: Maha Elsinbawi

\section{Abstract}

The purpose of the study was to explore and identify the experiences of mothers raising different mentally disabled child in the Egyptian society. Thirty mothers of children with mental disabilities have been selected and interviewed. They were diagnosed as Down syndrome (10 cases), Fragile-X (10 cases) and 10 with Autism. The interviewing process included two phases; introductory, and in-depth questions about mothers' personal experiences in raising kids with special needs. The results of the interviews showed that $90 \%$ of these mothers were literate, $63 \%$ end up divorced and $66 \%$ leaved their jobs to take care of their special needs kid. Sadness, guilt, shame and isolation were some of the feelings of mothers who participated in this research, in addition to the overwhelm of being stigmatized by the society. Findings highlighted that provision of adequate education, health care and stigma were the main issues for mothers. The study reported that Egyptians do not have the culture of the psychiatrist. Despite considerable progress in recent years, Egypt is still marked by discriminatory attitudes which affect children with disabilities and their mothers. The study concluded that despite the autistic associations programs to increase public awareness about Autism, yet fragile-X still remains poorly understood for most of the Egyptians. We discovered that mothers of children with Fra X syndrome and autistics were less optimistic than those with Down syndrome mothers. Study suggested strategies to help ease the stigmatization included providing simple information about genetic diseases that non-medical individuals can easily grasp.

Keywords: Stigmatization- Mothers of Special Needs Kids-Autistic, Fra X and DS Kids- Egyptian Society- Cultural norms.

Copyright @ 2020: This is an open-access article distributed under the terms of the Creative Commons Attribution license which permits unrestricted use, distribution, and reproduction in any medium for non-commercial use (NonCommercial, or CC-BY-NC) provided the original author and source are credited.

\section{Mothering a Child with Mental Disability in Egyptian Culture Perceptions of Stigma}

Negative stereotypes have been tied to concept of mental disabilities across the world [1]. Understanding the cultural context and what is normative within a particular cultural group is essential to the practice, with different diagnoses of disability likely to have different meanings to mothers from different cultural backgrounds [2]. Cultural affiliations such as religion, linguistics, and the racial origin of an individual's ancestors play a great role in the formation of the society. The Egyptian culture has had a unique way in preserving its cultural heritage, like the consanguinity marriage. Al-Kandari and Al-Kandari [3], defined consanguinity to be the amalgamation between two spouses who are biologically related and belonging to the same kinship group. Children with mental disabilities have long been discriminated against and were often considered among the minority groups that experienced marginalization in many societies. The social model of disability has been applied in this study to provide a framework for understanding how society perceives children with disabilities and their mothers, and how mothers perceive themselves and their disabled children.

Science highlighted the fact that the environmental factors may affect the genetic diseases, and some others because of genes that were manifested by special circumstances like consanguine marriages. Biological tolerance is governed primarily by the anatomical and functional structure of the body, which is largely determined by genetic factors transmitted through generations. But since the environmental factors have strong effects on the manifestation of some genetic disorder, culture is also partially responsible for the endorsement of some genetic diseases. 


\section{The norms of marriage in the Egyptian Culture}

Culture is the output of interaction of human beings as special creatures with the physical, and social environment that result in creating standard social norms. The precise definition of culture from one dimension will only cause the focus on the descriptive side and ignoring other elements that affects it, like the aspects of collective belonging and participation to groups [4].One of the most more prevalent cultural aspects among the Arab population in general and Egyptians in particular is the phenomenon of consanguinity. To preserve the traditions, the culture and the clean blood in the family, it is important to marry someone whose parents and ancestors have a good reputation and share the same values, beliefs and lifestyles. Another reason why the marriage of the cousins is so popular in the Egyptian culture is because of the inheritance of land. Since Egypt is considered an agricultural country, the value of land is very appreciated. And because a woman is deprived of her legal and religious right of controlling her own inheritance, marrying her cousin represents a "delusional" guarantee that her husband will protect her inheritance (especially if it's land) on her behalf, and that the land will remain in the family. It is culturally accepted that people with specific mental disabilities "are often considered superior rather than inferior due to the fact that they possess (blessing), and are able to pass it on and bless others"

Women having a blood relationship with husbands were more likely to report having ever been subjected to marital control behaviors, emotional and physical violence by their husbands, compared to those without such relationship [5]. The consequence of consanguineous marriages leads to sudden increase in the number of homozygous diseased individuals with fewer chances of mating and reduced chances of survival, confining the transmission of disease alleles to future generations. Findings show significant association between consanguinity and experience of emotional violence in Egypt and Jordon [6]. Consanguineous couples may inherit deleterious lethal genes to their offspring from common ancestors, which may result in prenatal, neonatal, and child morbidity or mortality [7]. Understanding the perceptions of what caused the birth of a disabled child, whether genetics or environmental or nutritional factors, the genetic susceptibility was the most frequently reported cause [8], and belief in this played a central role in stigmatization: mothers who gave birth to disabled children were automatically perceived as having 'faulty bodies'. A number of studies also revealed that in Egypt and the Middle East, fathers of children with mental disabilities are rarely active in taking care of them, rather it is the mother's responsibility.

Despite the fact that consanguinity, has been associated with adverse child health outcomes, stillbirths, spontaneous abortions and the increases in the risk of congenital anomalies and autosomal recessive diseases [9], it still occurs heavily in various areas of the Middle East. Studies of parental consanguinity in the Egyptian population showed a frequency ranging from 33 to $42 \%$ [10, 11]. First cousin's marriage was reportedly higher in rural areas $(59.9 \%)$ than in semi-urban and urban areas $(23.5 \%$ and $17.7 \%$, respectively) [12].

A mental disability is characterized by someone having an IQ below 70 (two standard deviations below the mean of 100 in the population), as well as significant difficulty with daily living such as self-care, safety, and communication. Examples are Fragile X syndrome, Down syndrome and Autism. Environmental factors also include problems that occur during pregnancy, such as viral or bacterial infections, Complications during birth, Exposure to toxins such as lead or mercury, Complications from illnesses such as meningitis, measles or whooping cough and Malnutrition.

The purpose of this study was to gain insight into the experiences of mothers caring for children with mental disabilities in relation to the limited resources in Egypt and to address the consequences of raising children with Fra X, autism and DS in Egypt.

\section{Mothers of Children with Disabilities}

Thirty mothers of children with mental disability were included in the study, they were selected from the out-patient Clinic for special needs, Center of Excellence, National Research Centre. We chose mothers who have children with the following mental disability:

Ten children had Fra $\mathrm{X}$ syndrome, 10 diagnosed as Down syndrome and 10 had autism (Table-1). Their enrollment in the study was based on the clinical picture and Laboratory results, the fragile $\mathrm{X}$ syndrome group included 10 males, their diagnosis was confirmed by DNA analysis using polymerase chain reaction (PCR) [13]. Group of children with Down syndrome diagnosed by chromosomal analysis. All children had free trisomy 21 except one child had DS,21\21 Translocation. The diagnosis of the Autistic disorder group was accomplished using three psychometric questionnaires/tests assessments; Diagnostic and Statistical Manual of Mental Disorders, Fourth Edition, Text Revision (DSM-IV-TR), Childhood Autism Rating Scale (CARS) [14] and Autism Diagnosis Intervention-Revised (ADI-R) and recent advancements in the field [15].

\section{METHODOLOGY}

In order to discover the feelings of the mothers of children with mental disability, we conducted personal interviews with 30 mothers. These mothers (along with their children) attended the clinic for children with special needs for genetic diagnosis and 
counseling services, National Research Center (NRC). Demographic data of the studied mothers and children (Table-1). Positive consanguinity was present in 14 women, representing almost $50 \%$ of the total participants. They all approved (and signed a consent) to participate in our 2 phases interviewing processes, which was approved by the Institution Ethical Review Board (medical research ethics committee at National Research Centre, Cairo, Egypt) according to Helsinki Declaration 1975 revised in 2008. In our interviewing dialogue, we tried to keep the questions simple and in the slang Arabic language to give the ease and comfort to the moms.

Since these mothers expressed that they had lived with silence and loneliness regarding their own feelings for many years, we had to exert extra effort to establish an interview relationship of mutual trust and respect. We wanted to explore on a more profound and intimate level, to highlight and refine their true feelings regarding feminist theories of mother-blame in the Egyptian culture.

\section{The Interviews}

The first phase was introductory about the participant mothers that included general questions like name, age, social status, and the case of their child. It was mainly important in order to create a relationship with these women, make them feel at ease by offering them food and drinks, and maintaining the discussion and the information flowing. We also asked them to maintain the spirit of harmony and understanding. The second phase was mainly a conversation that included in depth questions (Appendix 1).

These interviews were conducted with each participant on her own, and two observers were present at each interview. The venue of the interviews was inside the clinic's office of the National Research Centre in Cairo, Egypt.

\section{RESULTS}

We created a theory of change where we grouped the barriers that mothers of children with mental disability identified during the interviews, and how to overcome them in order to reach the desired outcome (Figure-1).

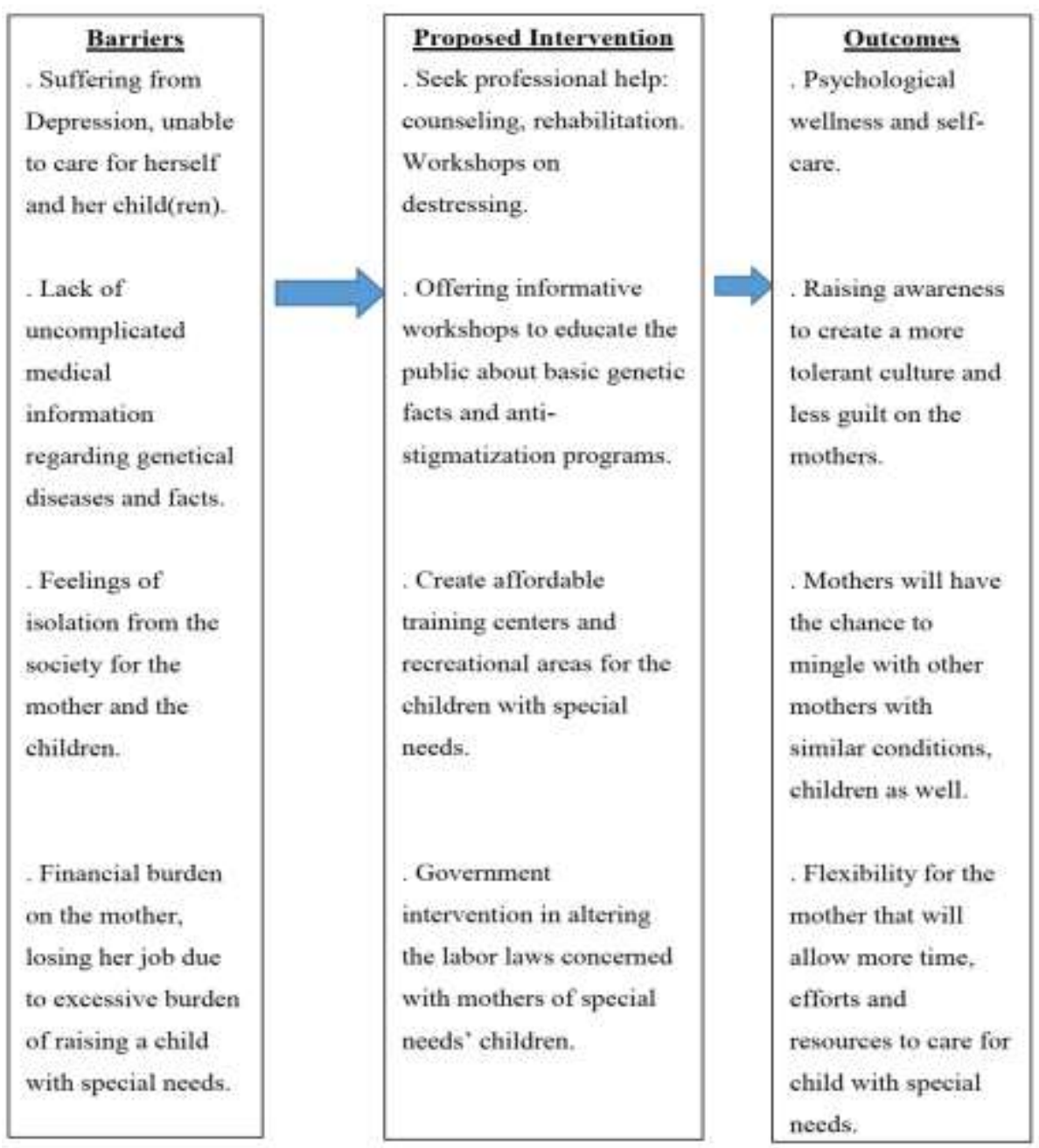

Fig-1: Theory of Change to Minimize Stereotyping and its Negative Effects on Mothers of Children with Mental disability Source: Theory of change adapted from Scho et al., (2018). Int. J. Environ. Res. Public Health 2018, 15, 2746; doi:10.3390/ijerph15122746 [27] 


\section{Appendix 1: Interview Questions}

How are parents of children with mental disability treated by the community?

How do mothers feel when they are treated badly?

What are the attitudes/feelings of the general public towards abnormal child?

What are people's fears about disabled child?

What messages in the media promote stigma?
How are people with mental disability children treated by the community?

How do mothers feel when their kids with mental disability are treated badly?

Who do you feel stigmatize you? In what forms do the stigmatization occur?

Where do you feel more stigmatized?

Table-1: Descriptive

\begin{tabular}{|c|c|c|c|c|c|c|c|}
\hline \multirow{2}{*}{$\begin{array}{l}\text { Participant } \\
\text { Mother }\end{array}$} & \multirow[t]{2}{*}{ Education } & \multirow[t]{2}{*}{ Occupation } & \multirow{2}{*}{$\begin{array}{l}\text { Marital } \\
\text { Status }\end{array}$} & \multirow{2}{*}{$\begin{array}{l}\text { Family } \\
\text { Composition }\end{array}$} & \multirow[t]{2}{*}{ Consanguinity } & \multicolumn{2}{|c|}{ Child Characteristics } \\
\hline & & & & & & Age Ys & Type of disability \\
\hline M1 & High School & Leave her Job & divorced & 3 children & First cousins & $5 y$ & Autism \\
\hline $\mathrm{M} 2$ & High School & House wife & Married & 4 children & First cousins & $4 \mathrm{ys}$ & Autism \&ADHD \\
\hline M3 & University & Leave her Job & divorced & 3 children & First cousins & $5 y s$ & Autism \\
\hline M4 & High School & Leave her Job & divorced & 2 children & First cousins & $4 y s$ & Autism with seizures \\
\hline M5 & University & House wife & divorced & 4 children & Not related & 3ys & Autism \\
\hline M6 & High School & Leave her Job & divorced & 2 children & Not related & 3ys & Autism \\
\hline M7 & None & Leave her Job & divorced & 4 children & First cousins & $4 y s$ & Autism \&ADHD \\
\hline M8 & High School & Leave her Job & divorced & 3 children & First cousins & 4ys & Autism with seizures \\
\hline M9 & University & Leave her Job & married & 2 children & Not related & $2 \mathrm{ys}$ & Autism \\
\hline M10 & High School & Leave her Job & divorced & 3 children & First cousins & $3 y s$ & Autism \&ADHD \\
\hline M11 & High School & Leave her job & divorced & 5 children & Not related & 4 ys & DS, trisomy 21 \\
\hline M12 & University & Leave her job & divorced & 3 children & First cousins & $3 \mathrm{ys}$ & $\begin{array}{l}\text { DS,21\21 } \\
\text { Translocation }\end{array}$ \\
\hline M13 & High School & House wife & $\mathrm{m}$ & $1 \mathrm{cl}$ & Not related & 4 ys & $\begin{array}{l}\text { DS, with autistic } \\
\text { features }\end{array}$ \\
\hline M14 & High School & Leave her job & divorced & 2 children & Not related & 3 ys & DS, trisomy 21 \\
\hline M15 & None & House wife & Widow & 5 children & First cousins & 2 ys & DS, trisomy 21 \\
\hline M16 & High School & Leave her job & divorced & 3 children & Not related & 3 ys & DS, trisomy 21 \\
\hline M17 & High School & House wife & divorced & 3 children & Not related & 2 ys & DS, trisomy 21 \\
\hline M18 & None & House wife & married & 4 children & Not related & 2 ys & DS, trisomy 21 \\
\hline M19 & University & Leave her job & married & 2 children & First cousins & 4 ys & DS, trisomy 21 \\
\hline M20 & University & Leave her job & married & 2 children & Not related & $3 \mathrm{ys}$ & DS, trisomy 21 \\
\hline M21 & High school & Leave her Job & married & 3 children & Not related & $5 \mathrm{ys}$ & Fra X syndrome \\
\hline M22 & High school & Leave her Job & married & 2 children & Not related & 4 ys & Fra $X$ syndrome \\
\hline M23 & University & Leave her Job & divorced & 3 children & First cousins & $5 \mathrm{ys}$ & Fra $\mathrm{X}$ syndrome \\
\hline M24 & None & House wife & divorced & 1 child & Not related & 3 ys & Fra X with autism \\
\hline M25 & High school & Leave her Job & divorced & 2 children & First cousins & 4 ys & Fra $\mathrm{X}$ with autism \\
\hline M26 & University & House wife & divorced & 3 children & First cousins & $3 y s$ & Fra X syndrome \\
\hline M27 & University & Leave her Job & married & 4 children & Not related & 4 ys & Fra $X$ syndrome \\
\hline M28 & High school & House wife & married & 2 children & Not related & $5 \mathrm{ys}$ & Fra X syndrome \\
\hline M29 & University & Leave her Job & divorced & 3 children & Not related & 4 ys & Fra $\mathrm{X}$ with autism \\
\hline M30 & High school & House wife & divorced & 4 children & First cousins & $3 \mathrm{ys}$ & Fra X with autism \\
\hline
\end{tabular}

\section{DISCUSSION}

To stigmatize is to label people and see them as different and inferior because of a certain different attribute they have, which creates a social distance [16]. These mothers acknowledged their feelings of stigmatization, in addition to the feelings of guilt, anger and loneliness. Which totally maps the reported feelings of "rage" and "overwhelms" experienced by various other mothers in the same situations of raising and caring of kids with special need [17].

Deep-rooted cultural ideas about women and motherhood led to these women's marginalization and segregation. The husband usually leaves the moral and financial support for his disabled child (ren) to their mother. He starts a new life; most probably with a new wife who would have a "cleaner blood", as described by one of the participants, and will be able to give him normal children. The mother is then left alone with the financial and emotional burden of raising the child (ren) with special needs on her own and becomes a divorced woman, which induced the feelings of her stigmatization in the Egyptian society. The outlook towards divorced women in the Egyptian society is demeaning and full of shame.

The "mother in law" phenomenon was also a very common cause of stigmatization against the mothers of children with mental disability, even more if the parents were first cousins. This result complies with other researchers reported by Loft [18], who reported that families with a child with disabilities or chronic illness have a higher risk of parental relationship 
termination, when compared to families where no diagnosis of child disability or chronic illness.

One of the other reflections of stigmatization against mother with mental disability was manifested in the fact that they were often required to leave their jobs. Whether it was because of discriminatory attitudes from their work organizations or because they had to spend more time taking care of their children, the result was the loss of their jobs and financial source.

These mothers were being alienated from their friends; they felt different and their kids were also different. The participants mothers felt they didn't belong with anyone because others didn't understand and didn't know the right way to communicate. They even felt estranged from themselves; they stopped grooming and taking care of themselves as women, as one mother explained that she believed that she felt her life stopped and that she won't be able to love anyone again, not even herself. With all the stress from the society pitying those mothers, they were shamed, blamed, and perceived as a destroyer of the family reputation. Being labeled as a "sinner" was among the harshest they had to face. The Egyptian society is described to be a religious one that believed in God, consequently if someone is given a burden it's usually because they committed a bad deed. And because children with mental disability were considered a burden or punishment, this indicated that the mother (alone) was a sinner who deserved the punishment. They lost the privilege of being respectable women in the society. Not only were their stigmatization consequences felt in their feelings of isolation and broken bonds with family and friends, it also affected their treatment-seeking behavior for themselves and their children. When asked why, most of them acknowledged that they could not go to treatment centers, because they feared the discriminatory label that they would be given when or if seen. Because they did not want to share information about their health problem with mothers of normal children, they ended up isolated and hopelessly living a stressful and stigmatized life. They also felt hopeless in understanding what was wrong with their kids, or for the improvement of their symptoms; like one participant hopelessly stated that: "I don't trust in the methods of education provided to disabled children. I don't know a lot of places and agencies that provide educational services for them. I can't train my disabled son at home and I feel much desire to stop the training sessions and treatment. I feel hopeless regarding the whole process."

Participant Children: Fra $\mathrm{X}$ is an $\mathrm{X}$-linked disorder caused by expansions of a CGG repeat in the untranslated (UTR) region of the FMR1 gene that arises due to the meiotic instability of certain alleles of this repeat tract. Premutation or full mutation males can receive their mutation from their mother as it is $\mathrm{X}$ linked disease. FXS has to be ruled out in families with consanguineous parents, before assuming that familial mental retardation is due to autosomal recessive gene defects [19]. Meanwhile, pre or full mutation males pass only a premutation to all of their daughters due to selective production of premutation allele bearing sperm. Females who carry the mutation may present with some degree of ID or behavioral problems and will transmit this mutation to half of their children. Fragile $\mathrm{X}$ Syndrome (FXS) is the most common monogenic Xlinked condition which causes variable degrees of Intellectual Disability (ID), autism spectrum disorder (ASD), delay in acquisition of speech and other cognitive skills [20].

Autism and Fragile $\mathrm{X}$ syndrome are intertwined. Autism is a complex disorder affecting neurologic development. It is characterized by deficits in social interaction, disrupted verbal and nonverbal communication, and restricted repetitive behavior and interests [21]. Despite that the characteristics of Autism being commonly found across cultures, the family experiences of caring for a child with ASD could be varied [22]. On the other hand, Down syndrome (DS) is a commonly occurring chromosomal abnormality. Over the last decades, great progress has been made in the medical and surgical treatment of these infants, yet, the perception remains that the DS infant is still not openly accepted by parents and society [23]. They reported that lack of social support, and the widespread stigmatization confronting children with DS and their families, hinder development of positive and empowering adjustments that would best serve the child's and the family's interest.

We reported that mothers of a child with a genetic (Fragile X syndrome) complained mainly from learning disability and hyperactivity. In many instances these mothers of Fra-X children are often positioned and judged in accordance with their child's behavior. The public has little knowledge about Fragile $\mathrm{X}$ syndrome [24, 25]. Despite the autistic associations programs to increase public awareness about autism, fragile-X syndrome still remains a poorly understood for most of the Egyptians. The stress of living with such individuals can affect the psychological well-being of family members. However, the difficulties produced by this disorder go beyond the family as a genetically transmitted disease affecting the whole society. We find out that mothers of children with Fra X syndrome and autistic children were less optimistic than those with Down syndrome mothers. On the other hand, lack of social support, and the widespread stigmatization confronting children with DS and their families, hinder development of positive and empowering their mothers.

The negative feelings of the stigmatization and serotypes were strongly present with the mothers of mentally disable children living in the Egyptian society. These depressive symptoms were also reported as 
common feelings in the mothers and caregivers of children with mental disability than the mothers of normal children in Japan as well; and as the number of children increases, the stress and stereotyping increase [26]. The study emphasized that stigmatization and subsequent discrimination towards women in general and mothers of mental disability children specifically are very remarkable in the Egyptian culture.

\section{RECOMMENDATIONS}

The first and most important suggested step to help these mothers, was to identify the stress they are facing, and then encourage them to seek professional help. The mothers can then use the available services like, counseling, testing, medical care, rehabilitation in addition to de-stressing workshops that proved to be effective in similar cases. The Understanding of what caused the birth of a disabled child, whether genetics or environmental or nutritional factors, in a simple way is crucial for the whole family in order to relief the total and complete blame placed on the mother. Providing knowledge about any disease is very commonly advised whenever stigmatization occurs to caregivers. This can happen through offering informative workshops, by allowing geneticists in collaboration with the community to offer trainings on anti-bullying and antistigmatizing of the mothers of kids with mental disability in the Egyptian society. The target of these workshops needs not only to be directed towards the community but also to the mothers themselves in order to clearly understand the case of their children and perhaps relief the guilt they are feeling.

It seems also needed to integrate the mothers of mental disability kids in the social life as an effective part of the solution, because the mother is the first caregiver to her kids. The stereotyping and feelings of shame that are prevailing over the mother and the kids will increase their isolation and create a dysfunctional society. The government needs to provide good and reasonable places for training/ treatment and recreation for these children at affordable prices. We emphasized the governmental significant role in providing alternatives to mothers with a disabled child. It needs to help in providing employment opportunities for her and hoping to modify the law to give flexibility to her employment conditions at the situation of divorce or having a disabled child.

\section{RECOMMENDATIONS FOR FUTURE RESEARCH}

We strongly recommend social scientists to team up with medical researchers especially geneticists, to research into more depth the negative effects that Society endures from the lack of medical information and vice versa. Since culture is originated from the society and the social norms, cultural changes occur when the public becomes more aware through the availability of medical facts and data.

\section{CONCLUSION}

Mothers raising children with mental disability, are often positioned and judged in accordance with their child's behavior. In order to eliminate stigmatization and achieve the desired level of tolerance and acceptance, it is very important to spread awareness regarding genetic diseases, and endorse the integration of these mothers and their children in the society.

Changing a culture is imminent if awareness is a priority, and if tolerance, inclusion and understanding are a mindful process to the society. These small steps of building bridges, can eventually lead to a changing culture in the Egyptian society that respect the woman and relief the burden of blame, shame and stigmatization.

Acknowledgements: Dr. Mona Anwar, for her assistance during the Interviewing processes

\section{REFERENCES}

1. Sadik, S., Bradley, M., Al-Hasoon, S., \& Jenkins, R. (2010). Public perception of mental health in Iraq. International Journal of Mental Health Systems, 4, 4-26.

2. Santos, R. M., \& Mccollum, J. A. (2007). Perspectives of parent child interaction in Filipino mothers of very young children with and without disabilities. Journal of Early Intervention, 29, 243-261.

3. Al-Kandari, Y., \& Al-Kandari, Y. (2018). Consanguineous marriage and its relationship with sociocultural variables in urban and Bedouin geographical regions in Kuwait. Arabian Humanities, 10.

4. Rathje, S. (2009). The definition of culture: An application-oriented overhaul. Inter-culture Journal, 8.

5. Shaikh, M. (2016). Domestic violence in consanguineous marriages-Findings from Pakistan demographic and health survey 2012-13. J Pak Med Assoc, 66(10), 1319-1322.

6. Usta, J., Khawaja, M., Dandachi, D., \& Tewtel, M. (2015). Consanguineous marriage: Protective or risk factor for intimate partner violence? Gender Based Violence: Perspective Africa, the Middle East and India. Springer, 117-134

7. Bhinder, M.A., Sadia, H., Mahmood, N., Qasim, M., Hussain, Z., Rashid, M., Zahoor, M., Bhatti, R., Shehzad, W., Waryah, A., \& Jahan, S. (2019). Consanguinity: A blessing or menace at population level. Ann Hum Genet, 83, 214-219

8. Dembo, R., Faber, J., Cristiano, J., Wareham, J., Krupa, J., Schmeidler, J., \& Terminello, A. (2018). Family problems, mental health and trauma experiences of justice-involved youth. Medical Research Archives, 6(1), 1-32 
9. Siong, K.H., Yeung, S., \& Leung, T. (2019). Parental consanguinity in Hong Kong. Hong Kong Medical Journal, 25, 192-200.

10. Tadmouri, G., Nair, P., Obeid, T., Al Ali, Khaja N., \& Hamamy, H. (2009). Consanguinity and reproductive health among Arabs. Reproductive Health, 6, 17-22.

11. Yamamah, G., Abdel-Raouf, E., Talaat, A., SaadHussein, A., Hamamy, H., \& Meguid, NA. (2012). Prevalence of consanguineous marriages in south Sinai, Egypt. J Biosoc Sciences, 14,1-9. Retrieved from: http://www.ncbi.nlm.nih.gov/pubmed/22583662

12. Shawky. R., El-Awady, M., Elsayed. S., \& Hamadan, G. (2011) Consanguineous matings among Egyptian population. Egyptian Journal of Medical Human Genetics, 12(2): 157-163.

13. Saluto, A., Brussino, A., Tassone, F., Arduino, C., Cagnoli, C., Pappi, P., Hagerman, P., Migone, N., \& Brusco, A. (2005). An enhanced polymerase chain reaction assay to detect pre- and full mutation alleles of the fragile $\mathrm{X}$ mental retardation 1 gene. The Journal of Molecular Diagnostics: $J M D, 7(5), 7:$ 605-612.

14. Schopler, E., Reichler, R. J., \& Renner, B. (1988). The childhood autism rating scale (CARS). Los Angeles: Western Psychological Services.

15. Siu, A. L., Bibbins-Domingo, K., Grossman, D. C., Baumann, L. C., Davidson, K. W., Ebell, M., García, F. A., Gillman, M., Herzstein, J., Kemper, A. R., Krist, A. H., Kurth, A. E., Owens, D. K., Phillips, W. R., Phipps, M. G., \& Pignone, M. P. (2016) Screening for autism spectrum disorder in young children: US preventive services task force recommendation statement. JAMA, 315(7), 691696.

16. Link, B. (2011). Stigma: Many mechanisms require multifaceted responses. Epidemiologia $E$ Psichiatria Sociale, 10(1), 8-11.

17. O'Halloran, M, \& Doody, O. (2013). Raising a child with disability and dealing with life events: A mother's journey. Journal of Intellectual Disabilities, 19(2), 41-47. .

18. Loft, L. (2014). Examining relationship termination among Danish parents with and without a child with disabilities or chronic illness. International Journal of Sociology, 41(1), 27-47.

19. Meguid, N. A., Ismail, M. F., El-Mahdy, R. S., Barakat, M. A., \& El-Awady, M. K. (2014). Simple molecular diagnostic method for Fragile X syndrome in Egyptian patients: Pilot study.ActaBiochim Pol, 61(2), 259-63.

20. Kamga, K., Nguefack, S., Minka, K., Tingang, E., Esterhuizen, A., Munung, S., De Vries, V., \& Wonkam, A. (2020). Cascade testing for fragile X Syndrome in a rural setting in Cameroon (SubSaharan Africa). Genes, 11(136), 1-11.

21. Geir, B., Meguid, N., El-Bana, M., Alexey, A., Saad, K., Dadar, M., Hemimi, M., Anatoly, V., Božena, H., Rene, K., Osredkar, O., \& Urbina, O. (2020). Oxidative stress in Autism spectrum disorder. Molecular Neurobiology, 57(5):23142332.

22. Riany, Yuliana, E., Monica, C., \& Pamela, M. (2016). Cultural beliefs about Autism in Indonesia. International Journal of Disability, Development and Education, 63, 623-40.

23. Huiracocha, L., Almeida, C., Huiracocha, K., Arteaga, J., Arteaga, A., \& Blume, S. (2017) Parenting children with Down syndrome: Societal influences. Journal of Child Health Care, 21(4), 488-497.

24. Meguid, N. A., Ismail, M. F., El-Mahdy, R. S., Barakat, M. A., \& El-Awady, M. K. (2014). Simple molecular diagnostic method for Fragile X syndrome in Egyptian patients: Pilot study. Acta Biochim Pol, 61(2), 259-63

25. Koschorke,M., Padmavati, R., Kumar, S., Cohen, A., Weiss, H., Chatterjee, S., Pereira, J., Naik, S., John, S., Dabholkar, H., Balaji, M., Chavan, A., Varghese, M., Thara, R., Patel, V., \& Thornicroft $G$ (2017). Experiences of stigma and discrimination faced by family caregivers of people with schizophrenia in India. Social Science \& Medicine, 178,66-77

26. Yamakao, Y., Tamiya, N., Izumida, N., Kawamura, A., Takahashi, H., \& Noguchi, H. (2016). The relationship between raising a child with a disability and the mental health of mothers compared to raising a child without disability in Japan. SSM- Population Health, 2, 542-548.

27. Wilbur, J., Bright, T., Mahon, T., Hameed, S., Torondel, B., Mulwafu, W., ... \& Polack, S. (2018). Developing behaviour change interventions for improving access to health and hygiene for people with disabilities: Two case studies from Nepal and Malawi. International journal of environmental research and public health, 15(12), 2746. 